\title{
O programa nacional de alimentação escolar como promotor de hábitos alimentares regionais
}

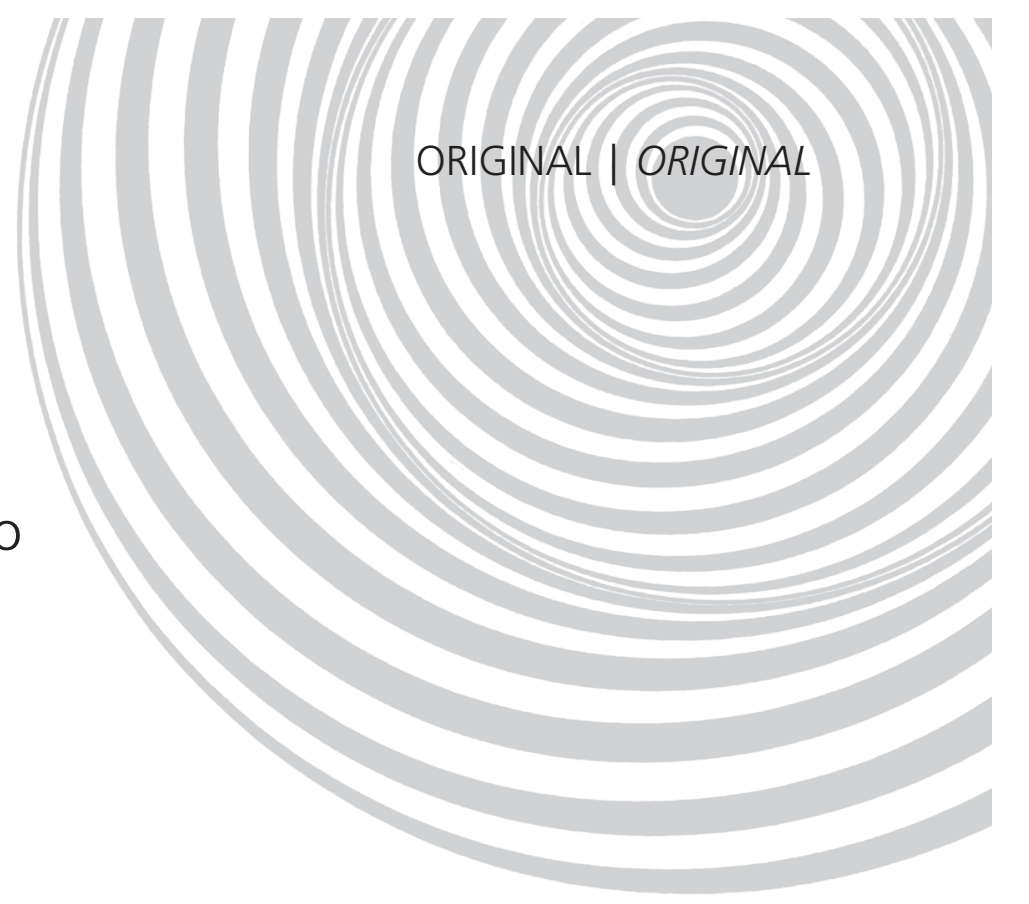

\author{
The national school food program \\ as a promoter of regional \\ food habits
}

Lorena Gonçalves CHAVES 1,2

Paula Nascente Rocha MENDES²

Rafaela Ribeiro de BRITO1,2

Raquel Braz Assunção BOTELHO

RE S U M O

\section{Objetivo}

O presente estudo analisa a utilização de alimentos e preparações regionais nos cardápios da alimentação escolar do ensino público brasileiro, bem como sua freqüência e sua elaboração por nutricionistas, sendo um estudo transversal e qualitativo.

\section{Métodos}

Os cardápios analisados foram oficialmente solicitados pelo Fundo Nacional de Desenvolvimento da Educação aos municípios e estados de todo o País. Do cálculo amostral, dos 2962 cardápios recebidos foram analisados 370, distribuídos proporcionalmente às regiões brasileiras, tomando-se como critério os cardápios do ensino fundamental da área urbana.

\section{Resultados}

Dos cardápios analisados, 63\% a 87,8\% foram elaborados por nutricionista. Entre as regiões, destaca-se a Sul, já que $86,5 \%$ dos cardápios contemplam pelo menos uma preparação regional no período de uma semana, enquanto na região Norte esse percentual cai para 38\%. A região Norte apresentou menor relação entre o número de cardápios elaborados por nutricionista e número de preparações regionais, enquanto que a região Sul apresentou maior relação.

${ }^{1}$ Ministério da Educação, Programa Nacional de Alimentação Escolar do Fundo Nacional de Desenvolvimento da Educação. Brasília, DF, Brasil.

2 Universidade Federal de Goiás, Faculdade de Nutrição, Pós-Graduação em Consultoria Alimentar e Nutricional. Goiânia, GO, Brasil.

${ }^{3}$ Universidade de Brasília, Departamento de Nutrição. Campus Universitário Darcy Ribeiro, Asa Norte, 70910-900, Brasília, DF, Brasil. Correspondência para/Correspondence to: R.B.A.BOTELHO.E-mail: <raquelbotelho@terra.com.br>. 
858 | L.G. CHAVES et al.

\section{Conclusão}

É necessário que os responsáveis pelo Programa incentivem e contemplem as preparações típicas ao hábito alimentar de cada região no cardápio da alimentação escolar e reforcem os meios de fiscalização desta prática.

Termos de indexação: Alimentação escolar. Hábitos alimentares. Políticas públicas. Programas e políticas de nutrição e alimentação.

\section{A B S T R A C T}

\section{Objective}

This cross-sectional and qualitative study analyzes the use of regional foods and preparations in the school menus of Brazilian public schools, as well as their frequency and the presence of dietitians.

\section{Methods}

The analyzed menus had been officially requested by the governmental area related to education in Brazil to the cities and the states of the entire country. For the sample, of the 2,962 menus received, 370 were analyzed, distributed proportionally by Brazilian regions. The criterion was the menus of the elementary schools located in urban areas.

\section{Results}

From the analyzed menus, 63 to $87.8 \%$ were made by dietitians. Among the regions, the south region stood out since $86.5 \%$ of the menus had at least one regional food per week. However, in the north region, the percentage of regional preparations dropped to 38\%. Furthermore, this region had the smallest relation between the number of menus prepared by dieticians and the number of regional preparations, while the south region had the greatest.

\section{Conclusion}

The professionals in charge of the National School Food Program need to encourage and consider typical regional preparations by including them in school menus and strengthen the monitoring of this practice.

Indexing terms: School feeding. Food habits. Nutrition programs and policies. Public policies.

\section{N T R O D U ÇÃ O}

A construção de políticas públicas que garantam os direitos do cidadão deve fazer parte da agenda dos que estão comprometidos com a educação, com a consolidação da democracia e com o combate às injustiças da sociedade contemporânea'.

Sob essa óptica, em 1953 surge a alimentação escolar, uma política compensatória da insegurança alimentar, que se constitui, atualmente, como a garantia universal do direito humano à alimentação, sendo uma das mais antigas e duradouras do mundo ${ }^{1,2}$.

Registros históricos demonstram que essa política já era utilizada em algumas comunidades, sendo custeada por sociedades filantrópicas. O poder público gradativamente foi dando suporte às ações de alimentação ao escolar, criando, em 1955, o Programa Nacional de Alimentação Escolar (PNAE).

Atualmente o Programa funciona por meio da transferência de recursos financeiros em caráter suplementar, de forma a garantir, no mínimo, 15\% das necessidades diárias dos alunos do ensino infantil e fundamental e $30 \%$ das necessidades diárias dos alunos das creches, das escolas indígenas e daquelas localizadas em áreas remanescentes de quilombos. Tem como objetivo atender às necessidades nutricionais dos alunos e contribuir para a formação de hábitos alimentares saudáveis durante sua permanência em sala de aula, colaborando para o seu crescimento, desenvolvimento, aprendizagem e rendimento escolar ${ }^{3}$. 
No intuito de enfatizar a formação de hábitos alimentares saudáveis, o PNAE propõe, em sua base legal, alguns princípios, dentre eles o respeito aos hábitos alimentares saudáveis, como as práticas tradicionais que fazem parte da cultura e da preferência alimentar local. Dessa forma, o Programa contribui para a preservação dos hábitos alimentares regionais ${ }^{3,4}$.

Para a elaboração do cardápio, o PNAE preconiza a presença do nutricionista, o qual assume a responsabilidade técnica pelo Programa, pois, sabe-se que o cardápio elaborado de acordo com a ciência da nutrição contribui para promoção de hábitos alimentares saudáveis, incentiva o consumo de alimentos regionais e promove melhoria da saúde da população atendida 5 .

No Brasil, país de amplitude continental, o panorama alimentar é complexo e peculiar ${ }^{6}$. Os fatores geográficos e as culturas dos povos negros, indígenas e brancos, associados à religiosidade popular, conduzem a diversidade de hábitos alimentares locais, caracterizando, assim, cada região do País. Por exemplo, na Bahia, a cultura alimentar é fortemente influenciada por tradições africanas e indígenas. Já na Região Norte, a cultura alimentar indígena tem maior influência, enquanto que no Sul os padrões europeus predominam? ${ }^{7}$.

A promoção da saúde no ambiente escolar vem sendo fortemente recomendada por órgãos internacionais ${ }^{8}$. Essa promoção é recomendada pelo PNAE, pois este abrange uma grande cobertura alimentar no País, cerca de 36 milhões de estudantes, proporcionando essa promoção no próprio ambiente escolar.

Assim sendo, é indispensável que as escolas forneçam um cardápio que seja capaz de atender às necessidades nutricionais dos alunos durante sua permanência em sala de aula, contribuindo para a preservação e o resgate da cultura alimentar brasileira.

Devido à escassez de dados referentes ao PNAE como promotor de hábitos alimentares regionais, e à recente modificação da Resolução do Programa, que traz princípios e diretrizes inova- doras, este trabalho tem como objetivo analisar os cardápios do Programa quanto à prática destes princípios e avaliar se estes são elaborados por nutricionistas.

\section{MÉ TO D O S}

Trata-se de um estudo transversal, não experimental, com finalidade exploratório-qualitativa, cujos instrumentos de dados foram os cardápios do Programa Nacional de Alimentação Escolar elaborados pelos estados, municípios e Distrito Federal, no ano de 2007.

O Fundo Nacional de Desenvolvimento da Educação (FNDE), autarquia gerenciadora do PNAE, por meio da Coordenação-Geral do Programa de Alimentação Escolar (CGPAE), solicitou às Prefeituras e às Secretarias de Educação dos estados do País o encaminhamento do cardápio de uma semana utilizado na alimentação escolar, com o nome da preparação, os ingredientes, per capita, a porção da preparação em gramas e em medidas caseiras, bem como o custo por aluno/ dia, com vistas à formação de banco de dados.

Do total de 5564 municípios existentes no Brasil, foram recebidos cardápios de 2950 municípios, aproximadamente $50 \%$ dos municípios brasileiros, resultando em um total de 3824 cardápios recebidos, sendo 2962 do ensino fundamental, com a seguinte distribuição: $7 \%$ da Região Norte, $34 \%$ do Nordeste, $8 \%$ do Centro-Oeste, $27 \%$ do Sudeste e $24 \%$ da Região Sul.

Utilizaram-se como critério para o presente estudo os cardápios referentes às escolas de ensino fundamental, localizadas em área urbana. Realizou-se o cálculo amostral de 370 cardápios $^{9}$, sendo escolhidos nesse universo de forma aleatória, por meio de sorteio, ficando o número de cardápios distribuídos proporcionalmente, para cada região do Brasil, da seguinte forma: 21 para o Norte, 119 para o Nordeste, 27 para o Centro-Oeste, 106 para o Sudeste e 97 para o Sul.

A tabulação dos alimentos e das preparações regionais oferecidas nas escolas foi feita 
segundo a lista de alimentos regionais, elaborada pelo grupo de pesquisa Preparações Regionais Saudáveis, da Universidade de Brasília, a partir de consulta bibliográfica a livros, páginas eletrônicas e periódicos, acrescida da lista de alimentos regionais do PNAE, instituída pelo Grupo de Trabalho intitulado "Elaboração da Lista de Produtos Básicos para o PNAE". Assim, verificou-se a presença ou não das preparações e o percentual encontrado por região.

\section{RESULTADOSE DISCUSSÃO}

Observa-se que dentre os cardápios analisados, $63 \%$ a $87,8 \%$ foram elaborados por nutricionistas. Nos demais cardápios, poucos apresentaram dados do responsável pela sua elaboração, no entanto, uma pequena parcela destes cardápios foi confeccionada por técnicos em nutrição, coordenadores do setor de merenda escolar, diretores de escola e, até mesmo, secretários de educação municipais. Em relação às regiões, pode-se verificar que o maior percentual de cardápios elaborados por nutricionista ocorreu na Região Nordeste, enquanto o menor percentual na Região Sudeste (Tabela 1).

Vale ressaltar que, apesar da obrigatoriedade quanto à presença do nutricionista responsável técnico, estabelecida pela Medida Provisória $n^{\circ} 2178$, que regulamenta o PNAE, foi

Tabela 1. Número de cardápios analisados do Programa Nacional de Alimentação Escolar, por Região do Brasil. Brasília (DF), 2007.

\begin{tabular}{lccccc}
\hline Regiões & Norte & Nordeste & Centro-Oeste & Sudeste & Sul \\
\hline $\begin{array}{l}\text { Cardápios } \\
\text { analisados (n) }\end{array}$ & 21 & 119 & 27 & 106 & 97 \\
$\begin{array}{l}\text { Cardápios } \\
\text { supervisiona- }\end{array}$ & 15 & 101 & 20 & 67 & 80 \\
$\begin{array}{l}\text { dos por nutri- } \\
\text { cionista (n) }\end{array}$ & & & & & \\
$\begin{array}{l}\text { Cardápios } \\
\text { supervisiona- } \\
\text { dos por nutri- } \\
\text { cionista (\%) }\end{array}$ & & & & & \\
\hline
\end{tabular}

constatada a ausência do nutricionista em muitos municípios do País, de forma mais acentuada na Região Sudeste, o que pode ser explicado pela proporcionalidade de municípios entre as regiões estudadas.

Em relação às preparações regionais nota-se que, dos cardápios analisados, 38,0\% a 86,5\% contêm pelo menos uma preparação regional no período de uma semana. Entre as regiões, destaca-se a Sul, uma vez que $86,5 \%$ dos cardápios contemplam preparações regionais, seguida das Regiões Nordeste e Sudeste, com $84 \%$. No entanto, ainda há regiões que não estão preservando e difundindo a cultura alimentar do País, e apresentam somente 59,3\% (Centro-Oeste) e 38\% (Norte) de cardápios com preparações típicas.

Esses dados refletem o cumprimento do princípio de respeito aos hábitos alimentares, das práticas tradicionais que fazem parte da cultura e da preferência alimentar local saudável preconizada pelo PNAE. Em algumas regiões brasileiras, observa-se que o Programa está contribuindo para a promoção de hábitos alimentares regionais. No entanto, para o Centro-Oeste e o Norte, é necessário que os órgãos responsáveis pelo PNAE incentivem o uso de preparações típicas no cardápio da alimentação escolar, bem como promovam fiscalizações e auditorias, visando a identificar os motivos desses resultados.

Para melhor discussão dos dados do presente trabalho, cada região será apresentada separadamente.

\section{Região Norte}

Dos 21 cardápios analisados, 38\% apresentaram preparações regionais em uma semana. Quatro preparações regionais foram mais freqüentes, na seguinte ordem: baião de dois (40\%), charque (30\%), farofa de charque (20\%) e açaí (10\%). Para tanto, a média de ocorrência das preparações regionais foi de 1,3, variando entre uma e duas vezes por semana.

A produção de alimentos de cada região também influencia na cultura alimentar local ${ }^{7}$. 
Destaca-se, nesta região, a produção de peixe; no entanto, a presença deste alimento foi observada, dentre os 21 cardápios analisados, apenas em um único cardápio, demonstrando pouca aquisição dos alimentos localmente. Dessa forma, esta região não segue as premissas do PNAE quanto à dinamização da economia local, extrapolando o uso de preparações características de outras regiões, como, por exemplo, a canjica, uma preparação típica das regiões Sul, Sudeste e Nordeste. A presença do açaí representa o impacto dessa fruta na região, produzida em maior escala. No entanto, outras frutas, como pupunha, murici e bacuri, poderiam ser incluídas nos cardápios.

Segundo a Pesquisa de Orçamentos Familiares (POF) ${ }^{10}$ de 2002-3003, realizada pelo Instituto Brasileiro de Geografia e Estatística (IBGE), na Região Norte foi constatada uma disponibilidade aquém da média nacional de leite e derivados, bem como de hortaliças, sendo também esta disponibilidade evidenciada na alimentação escolar analisada nesta amostra de cardápios. Cabe ressaltar que o incentivo ao consumo de hortaliças é essencial no Programa, e que a escola é um importante aliado para que as crianças possam adquirir o hábito de incluí-las na dieta durante a vida adulta.

O percentual de nutricionistas presentes na alimentação escolar da amostra $(71,4 \%)$ demonstra um aumento do número de profissionais responsáveis técnicos nesta Região, se comparado ao sistema de cadastro do FNDE, no qual $41 \%$ dos municípios apresentaram nutricionistas em 2006.

Nota-se que, mesmo apresentando um alto percentual de nutricionistas presentes como responsáveis técnicos pelo Programa, não houve uma relação direta com o número de preparações regionais, sendo que a Região Norte foi a que apresentou o menor percentual de preparações regionais do País. Dessa forma, o profissional ainda não está direcionando seu trabalho para os novos princípios do Programa e não promove eficazmente seu papel como formador de hábitos alimentares culturalmente referenciados.

\section{Região Nordeste}

Na Região Nordeste foram analisados 119 cardápios, os quais possuem, em média, 7 preparações regionais semanais, com variação de 5 a 10 preparações. Destes cardápios analisados, $84 \%$ apresentaram pelo menos uma preparação regional no período de uma semana. Em relação à média das preparações regionais, observa-se um valor de 1,4 preparações. Os estados de Pernambuco, Alagoas e Rio Grande do Norte apresentaram preparações regionais em todos os cardápios analisados, sendo que os dois primeiros estados e a Paraíba apresentaram média de duas preparações regionais por semana, enquanto os demais apresentaram média de uma preparação.

As preparações mais freqüentes nesta Região foram: cuscuz (29\%), canjica (16\%), baião de dois (13\%), arroz doce (8\%) e mingau de milho (8\%). Dessa forma, observa-se a predominância de preparações doces à base de milho, leite e arroz. Essas preparações doces justificam-se pela monocultura de cana-de-açúcar, que existia nesta Região, refletindo, assim, o uso demasiado de açúcar que variou de 10 a 39g per capita, nas preparações. Segundo Philippi et al. ${ }^{11}$, o consumo de açúcar refinado para um adulto não deve exceder $28 \mathrm{~g} / \mathrm{dia}$. Recomenda-se também que o consumo de açúcares e doces não ultrapasse duas porções ao dia. Diante disso, esse ingrediente deveria ser melhor controlado, modificando as preparações pelas técnicas dietéticas, visando receitas mais saudáveis e adequadas aos princípios e diretrizes do Programa.

Segundo o IBGE, o Nordeste é a terceira Região geográfica produtora de arroz do País, totalizando uma produção de 1245834 toneladas na safra de 2007, sendo que esse gênero alimentício tem sua maior produção na região Sul, com cerca de 7189310 toneladas neste ano ${ }^{12}$. De acordo com o Ministério da Agricultura, Pecuária e Abastecimento (MAPA), entre 1990 a 2005 o estado do Maranhão encontrava-se entre os maiores estados brasileiros produtores desse gênero alimentício ${ }^{13}$, e suas principais preparações 
regionais na alimentação escolar foram à base de arroz, como maria-izabel e arroz doce. Isso reflete a dinamização da economia local nesse estado.

Segundo a Pesquisa de Orçamentos Familiares, a disponibilidade do leite na Região Nordeste está bastante aquém da média nacional e a sua produção nesta Região ${ }^{10}$ encontra-se em quarto lugar, de 1990 a 2005, segundo dados do MAPA $^{14}$. Já a produção do milho está concentrada na Região Sul, assim como a de leite.

Destaca-se, nesta Região, o uso de gêneros alimentícios cuja sua principal produção está na Região Sul, refletindo a não observância dos princípios norteadores do PNAE quanto à dinamização da economia local, bem como o respeito da vocação agrícola, com exceção do estado do Maranhão pela produção de arroz.

Em relação às preparações, segundo Botelho ${ }^{15}$, em restaurantes self-service na Região Nordeste também foi encontrada a preparação baião-de-dois como a mais servida em Fortaleza, no Ceará (58\%) e Teresina, no Piauí (47\%), ressaltando a importância dessa preparação na cultura da Região estudada. Isso demonstra o simbolismo para a população brasileira da junção do arroz estimado como um alimento fraco e do feijão considerado forte, compondo uma preparação essencialmente nutritiva. Dessa forma, nota-se que a alimentação escolar ofertada nesta Região tenta, em alguns momentos, preservar a cultura alimentar em consonância com a identidade cultural do País.

Embora Pernambuco, Alagoas e Rio Grande do Norte tenham contemplado preparações regionais em todos os cardápios da amostra, não foi observada relação direta com os cardápios elaborados por nutricionistas, que correspondiam a $75,0 \%, 66,6 \%$ e $71,0 \%$ em relação ao total de cardápios analisados, respectivamente. No entanto, no Piauí e na Paraíba, todos os cardápios analisados foram elaborados por nutricionista, e esses estados apresentaram média de uma preparação regional em uma semana.
Nesta Região, o percentual de nutricionistas presentes na alimentação escolar foi de $87,8 \%$, evidenciando um aumento de responsáveis técnicos, pois, segundo o sistema de cadastro do FNDE, em 2006 havia apenas 47,0\% dos municípios com nutricionistas.

\section{Região Centro-Oeste}

Dos 27 cardápios analisados, 59\% apresentaram de uma a duas preparações regionais por semana, com uma média de 1,3. Nesta Região, três preparações apresentaram maior freqüência, na ordem: galinhada (38\%), arroz carreteiro (24\%) e feijão tropeiro (19\%). Botelho et al..$^{15}$ também encontraram, em restaurantes de auto-serviço, grande oferta de feijão tropeiro em Goiânia e Brasília, e de arroz carreteiro em Campo Grande, também denominado Maria-Isabel na região.

Nota-se nesta Região a preponderância de preparações à base de arroz, gênero alimentício cuja produção está concentrada na Região Sul. No entanto, é um alimento que está presente no prato do brasileiro diariamente e que faz parte da sua identidade cultural.

Destaque, mais uma vez, para a preparação canjica, característica das Regiões Sul, Sudeste e Nordeste, a qual se apresentou freqüentemente nas Regiões Norte e Centro-Oeste, demonstrando uma forte influência de uma preparação típica de outras regiões.

Esta é uma região que herdou hábitos alimentares de várias localidades do Brasil. Entre os exemplos dessa culinária estão o churrasco gaúcho, o virado paulista, o feijão tropeiro de Minas Gerais, sendo este último, presente nos cardápios analisados. Essa mescla fornece maior abertura para oferta de preparações regionais. No entanto, não se observa na Região maior presença de alimentos regionais nos cardápios em relação a outras.

Em relação aos nutricionistas, $74 \%$ dos municípios contam com esse profissional, o que mostra ter havido um aumento quando comparado 
aos dados do sistema de cadastro do FNDE, segundo o qual somente $45 \%$ dos municípios apresentaram nutricionistas em 2006.

Nesta Região também se pode dizer que a presença de nutricionistas não resultou em maior número de cardápios com preparações regionais, demonstrando que, ainda, há profissionais que não seguem um dos princípios do Programa, o respeito às práticas tradicionais que fazem parte da cultura e da preferência alimentar local.

\section{Região Sudeste}

Na região Sudeste foram analisados 106 cardápios, sendo que $84 \%$ deles continham pelo menos uma preparação regional por semana. Destes, observou-se uma média de 1,23 preparações regionais em relação ao número de preparações totais, sendo que Minas Gerais foi o que apresentou maior média dos estados desta Região $(1,87)$. Este resultado pode ser atribuído ao fato de que neste estado, dos 55 cardápios analisados, apenas 3 deles não ofereciam nenhuma preparação regional.

Apesar de Minas Gerais apresentar o maior número de preparações regionais, não se observou uma relação direta entre cardápios supervisionados por nutricionista e maior freqüência de pratos típicos. No Rio de Janeiro $(n=3)$ todos os cardápios contavam com a supervisão de nutricionista, em São Paulo ( $n=42$ ), $76 \%$, enquanto que, em Minas Gerais, esse percentual caiu para $53 \%$.

Esta Região apresentou o menor número de nutricionistas, quando comparada às demais. No entanto, observa-se o aumento desse profissional atuando na alimentação escolar, pois, segundo sistema de cadastro do FNDE, em 2006 somente $44,0 \%$ dos municípios do Sudeste apresentavam responsáveis técnicos. As preparações regionais apresentadas com maior freqüência foram: canjiquinha (16,3\%), tutu de feijão $(15,5 \%)$, canjica $(14,0 \%)$, polenta com carne moída $(13,2 \%)$ e feijão tropeiro $(11,6 \%)$.

As preparações regionais identificadas ocorreram especialmente em Minas Gerais. Salienta- -se o predomínio de preparações à base de milho e feijão, semelhante às outras regiões apresentadas. Na literatura referente à Região Sudeste, a canjiquinha e o feijão tropeiro estão sempre presentes como preparações características ${ }^{16}$.

O Brasil é o terceiro maior produtor de milho e sua produção corresponde a 5,9\% da produção mundial. Desde 2001, o milho passou a ser o cereal de maior produção mundial, em decorrência da sua importância tanto para o consumo humano quanto animal. Também no Brasil, o milho é o mais expressivo dentre os cereais cultivados, com cerca de 40,8 milhões de toneladas de grãos produzidos, de acordo com a Companhia Nacional de Abastecimento (CONAB), em $2006^{17}$.

Dados referentes à produção agrícola apontam que o Estado do Paraná é o maior produtor nacional com $26 \%$ do total de milho produzido no País, seguido por Minas Gerais (13\%), Rio Grande do Sul (12\%), São Paulo (10\%) e Goiás (9\%), ou seja, dos cinco maiores produtores dois (MG e SP) são da Região Sudeste, correspondendo a 23\% da produção nacional ${ }^{18}$.

Com relação ao feijão, este é um dos componentes básicos da dieta alimentar da população e importante fonte de proteína para as classes economicamente menos favorecidas. O Brasil é o maior produtor mundial de feijão, e Minas Gerais, o primeiro maior Estado produtor, respondendo por, aproximadamente, $15 \%$ da produção nacional, de acordo com estatísticas do IBGE ${ }^{18}$.

A influência desse gênero na alimentação regional pode ser remetida à presença dos tropeiros, que durante os séculos XVII e XVIII designavam o conjunto de homens que transportavam gado e mercadoria no Brasil colônia da Região do Rio Grande do Sul até os mercados de Minas Gerais e, posteriormente, São Paulo e Rio de Janeiro.

A alimentação dos tropeiros era constituída por toucinho, feijão preto, farinha, pimenta-do-reino, café, fubá e coité (um molho de vinagre com fruto cáustico espremido). Nos pousos comiam feijão quase sem molho, com pedaços de carne 
de sol e toucinho (feijão tropeiro), que era servido com farofa e couve picada ${ }^{19}$.

Assim, observa-se a influência histórica, social e econômica tanto do milho como do feijão oferecidos na alimentação escolar desta Região.

\section{Região Sul}

Dos 97 cardápios analisados, 86,5\% apresentaram de uma a três preparações regionais, com média de 1,7 preparações regionais em uma semana. Dentre todas as regiões do Brasil, esta apresenta o maior percentual de cardápios com preparações regionais, observando-se, inclusive, o valor máximo com uma média de 10 preparações regionais por semana.

Nesta região, ressalta-se a presença da preparação polenta, a qual foi oferecida 38 vezes nos 97 cardápios analisados. Outras sete preparações também apresentaram maior freqüência, na ordem: arroz carreteiro (16,3\%), risoto (12,7\%), canjica $(10,6 \%)$, arroz com galinha (5,6\%), galinhada $(4,9 \%)$, sagu $(4,2 \%)$ e nega maluca $(2,8 \%)$.

A Região Sul destaca-se pela maior produção de arroz do País, concentrada no Rio Grande do Sul20, um alimento freqüentemente observado nas preparações dos cardápios analisados, excluindo apenas polenta, sagu e nega maluca.

No entanto, pela POF a Região Sul apresenta maior disponibilidade de frutas, o que não condiz com os alimentos apresentados nos cardápios nesta Região ${ }^{10}$.

A influência de outros países na Região Sul é demonstrada claramente pela presença de polenta, risoto e sagu nos cardápios, principalmente por haver muitos representantes da comunidade italiana.

O percentual de cardápios supervisionados por nutricionistas foi de $84,2 \%$, sendo o segundo maior percentual do país. Nesta região, pode-se dizer que houve uma maior relação do número de preparações regionais com o percentual de cardápios com supervisão de nutricionistas, podendo-se inferir que estes profissionais estão mais conscientes dos princípios do Programa que as demais regiões. Entretanto, não há referências de outros estudos quanto a essa evidência.

Dentre as preparações regionais mais freqüentes utilizadas no PNAE, obteve-se um total de 18 preparações distintas, dessas, $17 \%$ são consideradas prato principal, 22\% guarnições, $28 \%$ acompanhamentos e $33 \%$ sobremesas. A mesma preparação, de acordo com a nomenclatura utilizada pela Prefeitura ou Secretaria Estadual de Educação, poderia ser classificada como prato principal (carne com polenta) ou guarnição, como no caso da preparação polenta com carne. Esse dado reflete a importância de nomenclaturas corretas, conforme a quantidade de macro-nutrientes existentes nas preparações (Figura 1).

Este estudo mostra que qualquer intervenção na área ligada à alimentação e nutrição, principalmente quando envolve aspectos educativos, requer, como pré-requisito, um conhecimento detalhado não só da região, mas da localidade propriamente dita. A escolha de alguns alimentos, em detrimento de outros, define as características da cultura alimentar (costumes regionais, tradições familiares, crenças, hábitos e tabus).

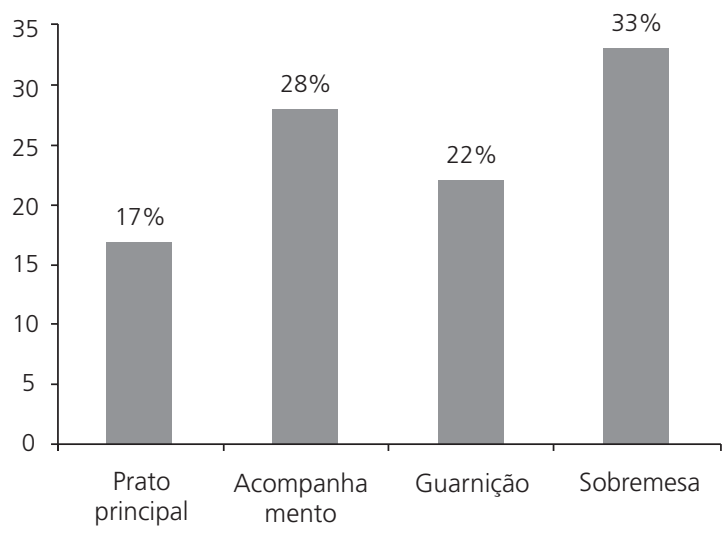

Figura 1. Percentual de tipos de preparações regionais do Programa Nacional de Alimentação Escolar no Brasil. Brasília (DF), 2007. 
A alimentação e o desenvolvimento de hábitos saudáveis são recursos educacionais versáteis, e têm o potencial de reunir toda a comunidade escolar, incluindo as famílias, em torno de uma discussão prática e motivadora ${ }^{21}$. Trata-se, portanto, do lugar ideal para o desenvolvimento de programas de saúde, mais especificamente de programas para a promoção de alimentação saudável|22.

Além disso, a escola exerce grande influência na formação de crianças e adolescentes, atores da comunidade escolar essenciais para a multiplicação de informações. A escola constitui um centro de ensino-aprendizagem, convivência e crescimento importante, e nela se adquirem valores vitais fundamentais ${ }^{22}$.

Dessa forma, o PNAE pode ser considerado também um instrumento pedagógico, não apenas por fornecer uma parte dos nutrientes de que o escolar necessita diariamente, mas também por se constituir em espaço educativo para alimentação saudável, quando, por exemplo, estimula a integração de temas relativos à nutrição ao currículo escolar23.

\section{ONCLUSÃ O}

A obrigatoriedade de haver nutricionista como responsável técnico pela alimentação escolar nos estados, no Distrito Federal e nos municípios atendidos pelo Programa Nacional de Alimentação Escolar está estabelecida na Medida Provisória $n^{\circ}$ 2178-36/2001, que rege o Programa. No entanto, os dados apresentados revelam que um pequeno percentual dos cardápios analisados não foi elaborado por nutricionistas, sendo este o único profissional de saúde habilitado para tal atribuição. Dentre os cardápios elaborados por nutricionista, poucos contemplavam preparações regionais.

O respeito à cultura alimentar regional nos cardápios do PNAE está aquém do desejado por um Programa que tem como premissa a promoção dos hábitos alimentares regionais saudáveis, com o intuito de dar continuidade a uma identidade cultural aprendida desde a escola. Isso é ratificado com a presença de algumas preparações regionais não saudáveis, como as ricas em açúcar na Região Nordeste, bem como a oferta de poucas preparações regionais.

Em relação às preparações regionais encontradas, vale ressaltar que no Brasil há uma mistura de culturas entre as regiões, expressando os cardápios um intercâmbio de preparações típicas, com destaque para a canjica, baião-de-dois, galinhada e arroz carreteiro, as quais, freqüentemente, estão presentes nos cardápios de várias regiões do País. Devido à mistura de culturas no Brasil, observa-se que algumas regiões não são produtoras do alimento regional consumido. Isso não inviabiliza que no passado tenham sido, todavia demonstra a permanência do hábito alimentar.

Diante dos resultados apresentados por este trabalho, destaca-se a importância da conscientização do nutricionista e dos demais responsáveis pelo setor de alimentação escolar, para a preservação e a recuperação da cultura alimentar brasileira, por meio da utilização das preparações regionais na alimentação escolar, visando à sua disseminação pelos escolares a por toda a sociedade brasileira.

Por fim, ressalta-se que o estudo teve como fonte de dados os cardápios referentes a uma semana da alimentação escolar planejada e, portanto, não reflete integralmente o padrão alimentar do escolar.

\section{COLABORADORES}

L.G. CHAVES participou na tabulação de dados, e a redação dos resultados das Regiões Norte e Centro-Oeste. P.N.R. MENDES participou na tabulação de dados e a redação dos resultados da região Sudeste. R.R. BRITO participou na tabulação de dados e na redação dos resultados da região Nordeste. R.B.A. BOTELHO orientou a pesquisa e participou na tabulação dos dados e no cálculo estatístico.

\section{REFERÊ NCIAS}

1. Spinelli MAS, Canesqui AM. Programa de alimentação escolar no estado de Mato Grosso: da 
centralização à descentralização (1979-1995). Rev Nutr. 2002; 15(1):105-17. doi: 10.1590/S1415-5273 2002000100011.

2. Coimbra M, Meira JFP, Estarling MBL. Comer e aprender: uma história da alimentação escolar no Brasil. Belo Horizonte: INAE; 1982. p.685.

3. Brasil. Fundo Nacional de Desenvolvimento da Educação. Resolução CD n 32, de 10 de agosto de 2006. Estabelece as normas para a execução do Programa Nacional de Alimentação Escolar. Diário Oficial da União. 200625 ago [acesso em 2008 jul 10]; n.154; Seção I. Disponível em: <http:// www.fnde.gov.br/home/index.jsp?arquivo=/ alimentacao_escolar/alimentacao_esc.html\# legislacao>.

4. Valente FLS. Inserção de componentes de alimentação e nutrição nas políticas governamentais e na estratégia nacional de desenvolvimento. Brasília: FAO; 1996. Relatório Final TCP/BRA/4453.

5. Brasil. Conselho Federal de Nutricionistas. Resolução $n^{\circ} 358$, de 18 de maio de 2005. Dispõe sobre as atribuições do Nutricionista no âmbito do Programa de Alimentação Escolar (PAE) e dá outras providências. Brasília; 2005.

6. Trigo M, Roncada MJ, Stewien GTM, Pereira IMTB. Tabus alimentares em região Norte do Brasil. Rev Saúde Pública. 1989; 23(6):455-64. doi: 10.1590/S 0034-89101989000600003.

7. Brasil. Ministério da Saúde. Guia Alimentar para a população brasileira: promovendo a alimentação saudável. Brasília: Ministério da Saúde; 2006.

8. Salay E. Composição de alimentos: uma abordagem multidisciplinar. Campinas: Unicamp; 2005.

9. Costa NP. Estatística. São Paulo: Edgard Blücher; 2002.

10. Instituto Brasileiro de Geografia e Estatística. Pesquisa de orçamentos familiares 2002-2003. Análise da disponibilidade domiciliar de alimentos e do estado nutricional no Brasil. Rio de Janeiro: IBGE; 2004.

11. Philippi ST, Latterza AR, Cruz ATR, Ribeiro LC. Pirâmide alimentar adaptada: guia para escolha dos alimentos. Rev Nutr. 1999; 12(1):65-80. doi: 10.1590/S1415-52731999000100006.

12. Instituto Brasileiro de Geografia e Estatística. Indicadores IBGE: levantamento sistemático da produção agrícola. Rio de Janeiro: IBGE; 2007 [acesso 2007 fev 2]. Disponível em: <http:// www.ibge.gov.br/home/estatistica/indicadores/ agropecuaria/lspa/textolspa012007.pdf.>

13. Brasil. Ministério da Agricultura, Pecuária e Abastecimento. Brasil: arroz, produção, área colhida e rendimento médio - 1990 a 2005. [acesso 2007 jun 13]. Disponível em: <http://www.agricultura. gov.br/pls/portal/docs/PAGE/MAPA/ESTATISTICAS/ PECUARIA/3.3.XLS>.

14. Brasil. Ministério da Agricultura, Pecuária e Abastecimento. Produção brasileira de leite por unidades da federação. [acesso 2007 jun 13]. Disponível em: <http://www.agricultura.gov.br/pls/ portal/docs/PAGE/MAPA/ESTATISTICAS/AGRICUL TURA_EM_NUMEROS_2005/03.02.05_1.XLS>.

15. Botelho RBA. Culinária regional: o nordeste e a alimentação saudável [tese]. Brasília: Universidade de Brasília; 2006.

16. Campos L. Serviço da Informação da Carne. Culinária típica brasileira. [acesso em 2007 jun 7]. Disponível em: <http://www.sic.org.br/tipica.asp>.

17. Brasil. Empresa Brasileira de Pesquisa Agropecuária. Cultivo do milho e do sorgo: sistemas de produção. 2a. ed. Brasília; 2006 [acesso 2007 maio 25]. Disponível em: <http://sistemasdeproducao. cnptia.embrapa.br/FontesHTML/Milho/Cultivo doMilho_2ed/index.htm>.

18. Instituto Brasileiro de Geografia e Estatística. Indicadores IBGE: Estatística da Produção Agrícola. Rio de Janeiro: IBGE; 2007 [acesso em 2007 maio 27]. Disponível em: <ftp://ftp.ibge.gov.br/Producao_ Agricola/Fasciculo_Indicadores_IBGE/2007_ 04.zip>.

19. Recco C. Curso de história: o tropeirismo no Brasil. [acesso 2007 abr 22]. Disponível em: <http://www. historianet.com.br/conteudo/default.aspx?codigo $=496 \mathrm{r}$.

20. Brasil. Atlas socioeconômico do Rio Grande do Sul. [acesso 2007 maio 25]. Disponível em: <http:// www.scp.rs.gov.br/ATLAS/atlas.asp?menu=265>.

21. Pinheiro ARO, Recine EG, Carvalho MFCC. As práticas alimentares saudáveis: a promoção da saúde no contexto da segurança alimentar e nutricional. In: Castro A, Malo M. SUS. Ressignificando a promoção da saúde. São Paulo: Hucitec; 2006. p.187-207.

22. Pelicioni MCF, Torres AL. A escola promotora de saúde. São Paulo: EDUSP; 1999. Série monográfica n.12.

23. Costa EQ, Ribeiro VM, Ribeiro ECO. Programa de alimentação escolar: espaço de aprendizagem e produção de conhecimento. Rev Nutr. 2001; 14(3): 225-9. doi: 10.1590/S1415-527320010003000 09.

Recebido em: 8/11/2007

Versão final reapresentada em: 22/7/2009 Aprovado em: 22/9/2009 